\title{
The effect of oxygen inhalation on cardiac biomarkers in patients presenting with acute ST-segment elevation myocardial infraction: A randomized clinical trial
}

\author{
Fatemeh Poorahmadieh ${ }^{1}$, Naiire Salmani*2 $\mathbb{D}$, Zohreh Kalani ${ }^{3}$ \\ Received: 21 Jan 2019 \\ Published: 12 Jan 2021
}

Abstract

Background: It is assumed giving oxygen to patients with acute myocardial infraction may increase the oxygenation of the ischemic tissue; however, the usefulness of oxygen in these patients has become a challenging topic. Thus, the present study aimed to determine the effect of oxygen inhalation on cardiac biomarkers in patients with acute myocardial infarction.

Methods: This randomized clinical trial study was performed on 2 groups of intervention and control within 2 days of admission to critical care unit (CCU). A total of 64 patients with ST-segment elevation acute myocardial infarction who referred to Zeyaei hospital, Ardakan, were selected using simple random sampling. In the intervention group, the pulse oximetry was monitored and they only breathed regular air and received supplemental oxygen in case their oxygen level dropped below 94\%. The levels of creatine kinaseMB and troponin I enzymes were measured. Data were analyzed using SPSS version 20 through repeated measure ANOVA, $t$ test, and chi-squared test. Significance level was set at 0.05 .

Results: This study showed that during the 48 hours of hospitalization, there were no significant differences between the 2 groups regarding the levels of creatine kinase-MB $(\mathrm{p}=0.509)$ and troponin $\mathrm{I}(\mathrm{p}=0.604)$.

Conclusion: Since the level of cardiac biomarkers is a sign of the extent of infracted area, it is assumed receiving supplemental oxygen in patients with acute myocardial infarction has no effect on decreasing the infracted area.

Keywords: Troponin I, Creatine kinase, Oxygen inhalation therapy, Myocardial infarction

Conflicts of Interest: None declared

Funding: Shahid Sadoughi University of Medical Sciences

*This work has been published under CC BY-NC-SA 1.0 license.

Copyright $($ Iran University of Medical Sciences

Cite this article as: Poorahmadieh F, Salmani N, Kalani Z. The effect of oxygen inhalation on cardiac biomarkers in patients presenting with acute ST-segment elevation myocardial infraction: A randomized clinical trial. Med J Islam Repub Iran. 2021 (12 Jan);35:6. https://doi.org/10.47176/mjiri.35.6

\section{Introduction}

Coronary heart disease is the leading cause of death worldwide (1). According to the American Heart Association in 2015, coronary heart disease (CHD) is the most common heart condition which causes 370000 deaths and 735000 heart attacks in the USA annually (2). The prevalence of this disease is also on the rise in Iran, increasing

Corresponding author: Dr Naiire Salmani, n.salmani@ssu.ac.ir

1. Department of Nursing, School of Nursing and Midwifery, Shahid Sadoughi University of Medical Sciences, Yazd, Iran

2. Meybod Nursing School, Shahid Sadoughi University of Medical Sciences, Yazd, Iran

3. Department of Nursing, School of Nursing and Midwifery, Research Center for Nursing and Midwifery Care, Shahid Sadoughi University of Medical Sciences, Yazd, Iran. from $20 \%$ to $45 \%$, accounting for almost $50 \%$ of all deaths annually (3). Acute myocardial infarction is one of the coronary heart diseases that is commonly caused by plaque rupture and the subsequent thrombosis (4). Acute myocardial infarction with ST-segment elevation is a type of myocardial infarction and since not every treatment

\section{$\uparrow$ What is "already known" in this topic:}

The use of oxygen in patients with acute myocardial infraction without monitoring the amount of arterial saturated oxygen is a common intervention. Studies have shown different effects of oxygen therapy on cardiac perfusion status; thus, further studies are needed in this regard.

\section{$\rightarrow$ What this article adds:}

The results of this study showed prescribed oxygenation based on monitoring arterial oxygen saturation does not have any effect on reduction of creatine kinase-MB and troponin I enzymes in patients with acute myocardial infraction. 
center has the necessary equipment, therapeutic guidelines for patients with myocardial infarction consist of prescribing nitrates, aspirin, and oxygen inhalation therapy before reperfusion (1).

It is assumed that giving oxygen to the patient may increase the oxygenation of the ischemic tissue and reduce pain, as a symptom of ischemia, and the infarct size (5). However, after conducting studies on the effects of oxygen, the usefulness of oxygen in these patients has become a challenging topic (6). Nevertheless, studies showed that giving oxygen to patients who are not hypoxic does not increase the amount of oxygen that reaches the heart and may even increase vascular resistance and blood pressure, and reduce cardiac output (7-9). It may also increase the myocardial damage by contracting coronary arteries (7). Moreover, oxygen therapy has the potential to worsen the reperfusion of the damaged area by releasing free radicals (10). Administering oxygen increases blood pressure and systemic vascular resistance and reduces heart rate and myocardial oxygen consumption. Coronary blood flow decreases in response to hyperoxia, which is the result of vascular constriction, regardless of initial $\mathrm{SPO}_{2}$ (11).

Through a vast study on 20 selected centers in 4 countries, Gregg et al (2009) concluded that using oxygen supersaturation was successful during percutaneous coronary intervention and reduced infarct size based on paraclinical parameters. According to their studies, the infarct size was $20 \%$ in the group with oxygen supersaturation and $26.5 \%$ in the control group (10). Ranchord et al (2012) conducted a research in the same field and found no significant differences in the amount of troponin and infarct size in people who had received high concentration oxygen compared with those who had received oxygen according to the pulse oximetry or breathed room air (9). A study by Stub et al (2015) showed that the mean peak levels of troponin and creatine kinase and the incidence of recurrent myocardial infarction and arrhythmia were higher in the oxygen group than in the control group. After 6 months, an increase in the infarct size was observed in patients in the oxygen group, according to the cardiac magnetic resonance imaging (7). The meta-analysis done by Nariman et al in 2018 showed that there was no statistically significant difference in the infarct size between the oxygen group and the group breathing regular air, with no signs of mortality rate being affected in the 2 groups. They stated that there is a need for more research in this field until enough evidences are found to determine whether or not oxygen is safe and harmless (12).

One of the interventions to minimize myocardial injury is to reduce oxygen demand and increase the myocardial oxygen supply through medications and administration of oxygen (13). The nurses' goal is to increase the cardiac output $(6,7,9,14)$. They often supply patients with oxygen at their request, without the doctor's order; however, this is against hospital instructions (15). In fact, it is not easy to say "yes or "no" to oxygen therapy in myocardial infarction; and several problems need to be solved in future studies. Evidence suggests that oxygen therapy in acute coronary syndrome and STEMI has turned into a standard care without accurate data (16). However, it is necessary for the nurses at intensive care units to consider signs and symptoms in the patients instead of routinely using oxygen and to replace the old routine methods with evidence-based methods (17). Also, nurses need to be trained and update their knowledge $(5,17,18)$ to obtain and maintain new information on medicines such as oxygen to assess hypoxia symptoms and to administer oxygen. The best method for providing clinical care is to ensure that nurses actions have the best possible outcome for the patients. Therefore, given the uncertainty about oxygen use or lack of use, it is necessary to reevaluate this treatment method and to perform clinical practices not as a routine, but based on patients' benefit and safety (15).

Therefore, based on the researcher's clinical experience in CCU regarding oxygen use in patients with acute myocardial infarction, along with the lack of evidence of the usefulness or uselessness of oxygen administration for patients with acute myocardial infarction, the present study aimed to determine the impact of oxygen therapy on cardiac biomarkers in patients with acute myocardial infarction.

\section{Methods}

This randomized clinical trial study was approved by the ethics committee of Shahid Sadoughi University of Medical Sciences, Yazd (ir.ssu.res.1396.168) and also registered on the Iranian Registry of Clinical Trials site (IRCT20180321039134N1). Considering the significance level of $5 \%$ and test power of $80 \%$, according to the standard deviation of troponin $(\mathrm{S}=7.2)$ based on Ranchord et al study (9), and aiming to achieve a significant difference of 2 units in the mean troponin in the intervention group compared to the control group (29 individuals and considering $10 \%$ drop), 32 individuals in each group were estimated. A total of 64 patients with acute myocardial infarction who were admitted to the cardiology department of Zeyaei hospital, Ardakan, during February 2017 and October 2017were included in the study. Informed consent (oral and written consent) was obtained from all participants, and they were not blind to the research.

$$
\mathrm{N}=\frac{\left(z \frac{\alpha}{c}+z \beta\right)^{2} * 2 s^{2}}{\left(\overline{x_{1}}-\bar{x} \overline{2}\right)^{2}}
$$

Patients were selected via simple randomization method and were randomly assigned into 2 groups of control and intervention through random numbers (Diagram 1); then, the number allocated to each individual in each group was placed in a separate envelope and was given to the ward nurse (the researcher's assistant). The inclusion criteria of the study were as follow: an ST-segment elevation of 0.1 $\mathrm{mV}$ in 2 contiguous limb leads or an ST-segment elevation of $0.2 \mathrm{mV}$ in 2 or more procardia leads in patients older than 18 years with less than 12 hours passing from their first ischemic symptoms; no previous history of myocardial infarction; and no respiratory diseases. Exclusion criteria were history of cardiogenic shock; interhospital or intrahospital patient transfer; and cardiac arrest at the time of admission. Also, dropout criteria were as follow: a cardiogenic shock during the study; a cardiac arrest during 
the study; patient's death; a patient's reluctance to continue the study; or being transferred to another ward or hospital during the study.

Patients who met the inclusion criteria were provided with necessary explanations about the study. Participants were included in the study on their own will and oral and written informed consent was obtained from them. In both groups, the Demographic Information Questionnaire and Clinical Evaluation Checklist, including the amounts of creatine kinase-MB and troponin I, were filled out. The control group underwent oxygen therapy after being admitted by the shift nurse according to the ward routines and received oxygen 4 to 5 liters per minute depending on the patient's tolerance through a mask or nasal cannula. The intervention group underwent blood oxygen monitoring and if their blood oxygen saturation was below 94\% $(6,14)$, oxygen therapy by simple face mask or nasal catheter was used according to the patient's choice until the arterial oxygen level reached $94 \%$ or higher. Once oxygen reached this level, oxygen therapy was stopped. $\mathrm{SPO}_{2}$ was controlled in all patients using Sazgan Gostar monitor finger probe. Also, routine treatment was done in the same way and included aspirin, nitrate therapy, and thrombolytic therapy with streptokinase or retavase, and heparin, according to what the physician had prescribed.

Considering that all patients were hospitalized in $\mathrm{CCU}$ within 48 hours after the admission, the duration of the study was considered to be 48 hours for each patient in both intervention and control groups. The enzyme creatine kinase-MB was measured based on the ward's routine in 3 sessions: at the moment of admission, 12 hours, and 24 hours after admission. Also, troponin I was measured in 3 sessions: at admission, 24 hours, and 48 hours after admission. Moreover, all the tests were performed at the

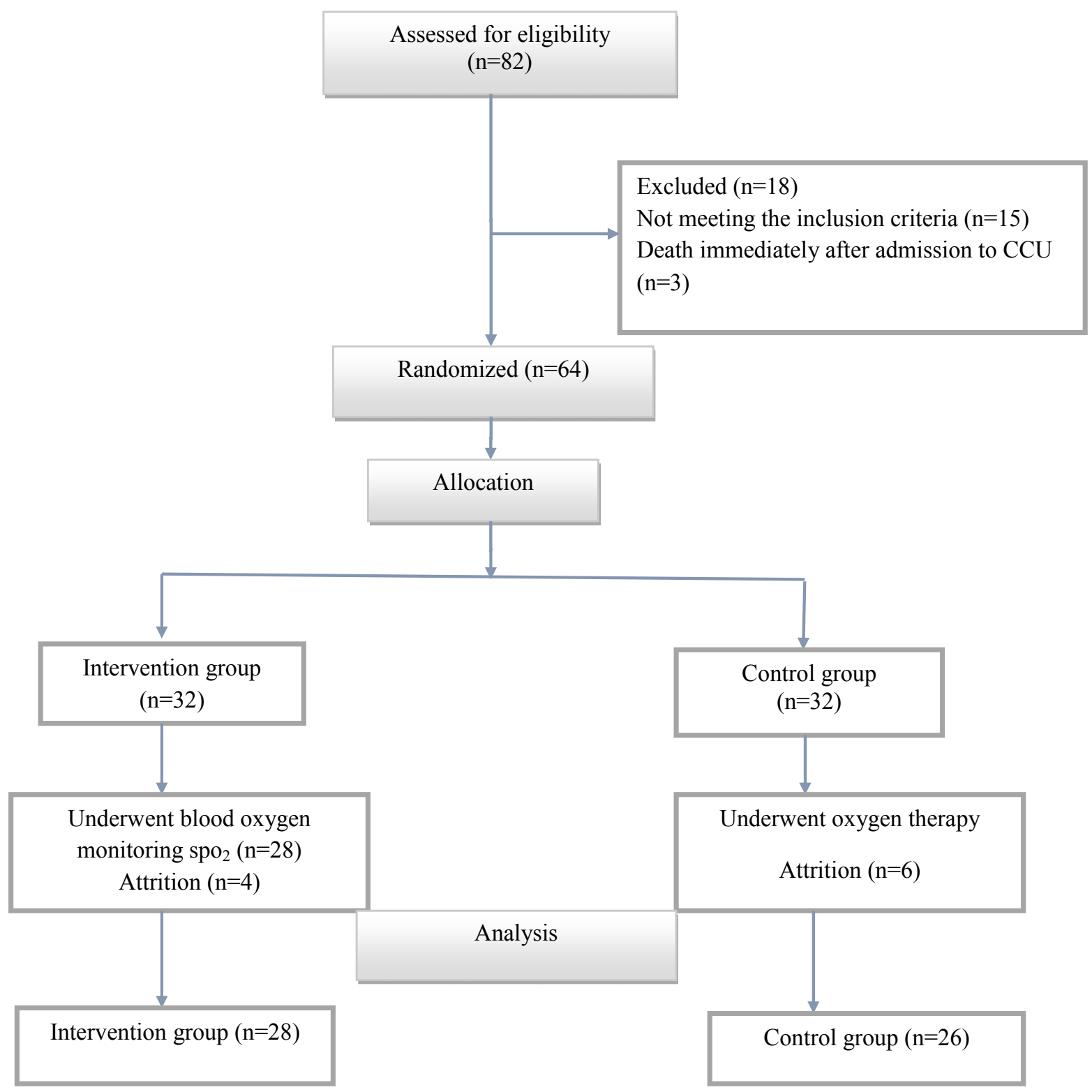

Diagram 1. CONSORT diagram shows the flow of participants through each stage of the randomized trial 
laboratory of Ziaee hospital by a technician and with a kit. Troponin I enzyme test was performed by the DAS device in Italy, and the minimum troponin I sensitivity measurable by the kit was $0.030 \mathrm{ng} / \mathrm{mL}$. CK_MB enzyme test was done by i-CHROMA device. With respect to sensitivity level, the least measurable amount of creatine kinase$\mathrm{MB}$ was 3 international units per liter.

\section{Statistical analysis}

Data were analyzed using SPSS version 20. The data on age were compared between the 2 groups using $t$ test. Chisquared test was used to compare the differences between the 2 groups in terms of gender, education level, occupation, and type of MI. The mean levels of enzymes were measured in 3 sessions in the 2 groups using the repeated measures ANOVA, and intergroup comparisons were made using t test. Also, $\mathrm{p}<0.05$ was considered significant and the power of analysis was $80 \%$ in all tests.

\section{Results}

The samples consisted of 64 patients, of whom 32 were placed in the intervention group and 32 in the control group. Four participants from the intervention group
(Three were sent to the provincial capital to do PCI and continue their treatment, and 1 died.) and 6 from the control group (Two were sent to the provincial capital to do PCI, 2 died, 1 had cardiac arrest and used a ventilator, and 1 was unwilling to participate.) were excluded from the study. Table 1 shows the demographic characteristics of the studied samples. The results of t test and chi-squared test did not show any significant difference between the 2 groups in terms of age, gender, education level, and occupation.

Table 2 shows the mean and standard deviation of enzymes examined during the 3 measurements. There was no statistically significant difference in the level of creatine kinase-MB in the 2 groups at admission $(\mathrm{p}=0.406), 12$ hours ( $p=0.524)$, and 24 hours after admission $(p=0.285)$.

Due to intergroup comparison, no statistically significant difference was found in the levels of the troponin I in the 2 groups at the time of admission $(p=0.324), 24$ hours $(\mathrm{p}=0.543)$ and 48 hours after admission $(\mathrm{p}=0.801)$ (Table $3)$.

Table 4 and Figures 1 and 2 show the results of the repeated measures ANOVA test. They demonstrate the effect of time and the interaction of time in the groups.

\begin{tabular}{|c|c|c|c|c|}
\hline Variable & & Control group & Intervention group & $\mathrm{p}$ \\
\hline \multirow[t]{2}{*}{ Age } & & $61.28 \pm 10.10$ & $56.57 \pm 13.34$ & 0.108 \\
\hline & Man & $20(76.9 \%)$ & $15(53.6 \%)$ & 0.076 \\
\hline \multirow[t]{4}{*}{ Sex } & Woman & $6(23.1 \%)$ & $13(46.4 \%)$ & \\
\hline & Illiterate & $9(36 \%)$ & $10(35.7 \%)$ & \\
\hline & Diploma & $12(48 \%)$ & $13(46.4 \%)$ & \\
\hline & Bachelor & $3(12 \%)$ & $5(17.9 \%)$ & 0.640 \\
\hline \multirow[t]{5}{*}{ Education } & Master & $1(4 \%)$ & $0(0 \%)$ & \\
\hline & Employed & $6(23.1 \%)$ & $5(17.9 \%)$ & \\
\hline & Worker & $7(26.9 \%)$ & $5(17.9 \%)$ & \\
\hline & Self-Employment & $1(3.8 \%)$ & $3(10.7 \%)$ & 0.507 \\
\hline & Housekeeper & $6(23.1 \%)$ & $4(14.3 \%)$ & \\
\hline \multirow[t]{7}{*}{ Occupation } & Unemployed & $6(23.1 \%)$ & $11(39 / 3 \%)$ & \\
\hline & Anterior & $14(53.84 \%)$ & $15(53.57 \%)$ & \\
\hline & Inferior & $4(15.38 \%)$ & $5(17.85 \%)$ & \\
\hline & Septal & $4(15.38 \%)$ & $3(10.71 \%)$ & 0.552 \\
\hline & Right Atrium & $1(3.84 \%)$ & $2(7.14 \%)$ & \\
\hline & Left Lateral & $1(3.84 \%)$ & $1(3.57 \%)$ & \\
\hline & Anteroseptal & $1(3.84 \%)$ & $2(7.14 \%)$ & \\
\hline Type of MI & Anterolateral & $1(3.84 \%)$ & $0(0 \%)$ & \\
\hline
\end{tabular}

Table 2. The comparison of changes in creatine kinase in the studied groups in different measuring sessions

\begin{tabular}{|c|c|c|c|c|}
\hline Creatine kinase-MB measuring session & Group & Mean and Standard deviation & $\begin{array}{c}\mathrm{p} \\
\text { (T test) }\end{array}$ & Power \\
\hline At admission & $\begin{array}{c}\text { Intervention } \\
\text { Control }\end{array}$ & $\begin{array}{l}51.8 \pm 40.5 \\
42.8 \pm 25.9\end{array}$ & 0.406 & 0.79 \\
\hline 12 hours after admission & $\begin{array}{c}\text { Intervention } \\
\text { Control }\end{array}$ & $\begin{array}{l}183.7 \pm 103.3 \\
207.6 \pm 129.9\end{array}$ & 0.524 & 0.81 \\
\hline 24 hours after admission & $\begin{array}{c}\text { Intervention } \\
\text { Control }\end{array}$ & $\begin{array}{c}97.0 \pm 58.6 \\
117.6 \pm 61.36\end{array}$ & 0.285 & 0.82 \\
\hline
\end{tabular}

Table 3. The comparison of changes in troponin I in the studied groups in different measuring sessions

\begin{tabular}{|c|c|c|c|c|}
\hline Troponin I measuring session & Group & $\begin{array}{c}\text { Logarithmic mean and standard } \\
\text { deviation }\end{array}$ & $\begin{array}{c}\mathrm{p} \\
\text { (T test) }\end{array}$ & Power \\
\hline At admission & $\begin{array}{c}\text { Intervention } \\
\text { Control }\end{array}$ & $\begin{array}{l}0.16 \pm 0.41 \\
0.24 \pm 0.32\end{array}$ & 0.324 & 0.81 \\
\hline 24 hours after admission & $\begin{array}{c}\text { Intervention } \\
\text { Control }\end{array}$ & $\begin{array}{l}0.62 \pm 0.32 \\
0.69 \pm 0.42\end{array}$ & 0.543 & 0.80 \\
\hline 48 hours after admission & $\begin{array}{c}\text { Intervention } \\
\text { Control }\end{array}$ & $\begin{array}{l}0.72 \pm 0.26 \\
0.71 \pm 0.43\end{array}$ & 0.801 & 0.80 \\
\hline
\end{tabular}




\begin{tabular}{|c|c|c|c|c|c|c|c|c|}
\hline Variable & & Source & Sum of squares & $\mathrm{df}$ & Mean Square & $\mathrm{f}$ & $\mathrm{p}$ & Power \\
\hline \multirow{5}{*}{ Troponin I } & \multirow[b]{2}{*}{ Within group } & Time & 6.4 & 2 & 3.2 & 38.06 & 0.001 & \multirow{3}{*}{0.81} \\
\hline & & Time \& group & 0.04 & 2 & 0.02 & 0.27 & 0.752 & \\
\hline & \multirow{3}{*}{ Between group } & Error & 6.4 & 76 & 0.08 & - & - & \\
\hline & & Group & 0.066 & 1 & 0.066 & 0.27 & 0.604 & \multirow{2}{*}{0.81} \\
\hline & & Error & 9.2 & 38 & 0.24 & - & - & \\
\hline \multirow{5}{*}{ Creatine kinase-MB } & \multirow[t]{3}{*}{ Within group } & Time & 445335.9 & 2 & 222667.9 & 48.8 & 0.001 & \multirow[t]{2}{*}{0.80} \\
\hline & & Time \& group & 6585.7 & 2 & 3292.8 & 0.72 & 0.428 & \\
\hline & & Error & 346602.3 & 76 & 4560.5 & - & - & \multirow{3}{*}{0.80} \\
\hline & \multirow[t]{2}{*}{ Between group } & Group & 4189 & 1 & 4189 & 0.44 & 0.509 & \\
\hline & & Error & 358177.9 & 38 & 9425.7 & - & - & \\
\hline
\end{tabular}

Moreover, no significant difference was observed in the changes in the amount of troponin I and CK-MB in the 2 groups in 48 and 24 hours, respectively, and $\mathrm{p}$ values were 0.604 and 0.509 , respectively.

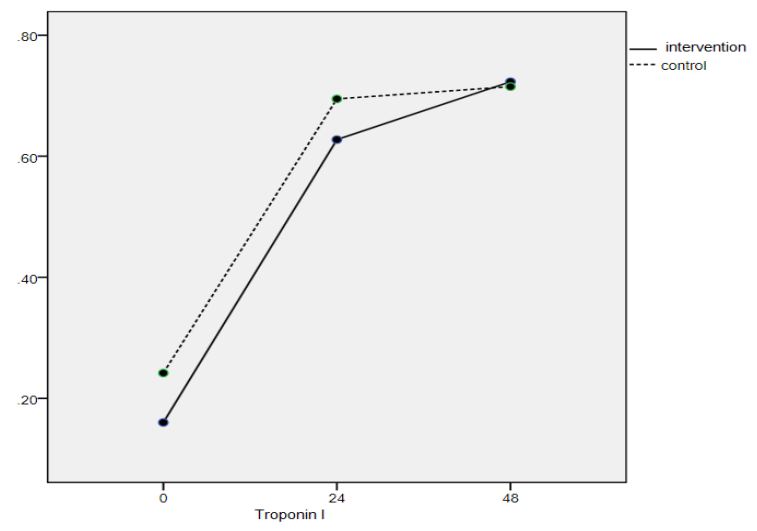

Fig. 1. Changes in troponin I enzyme during time between the 2 groups

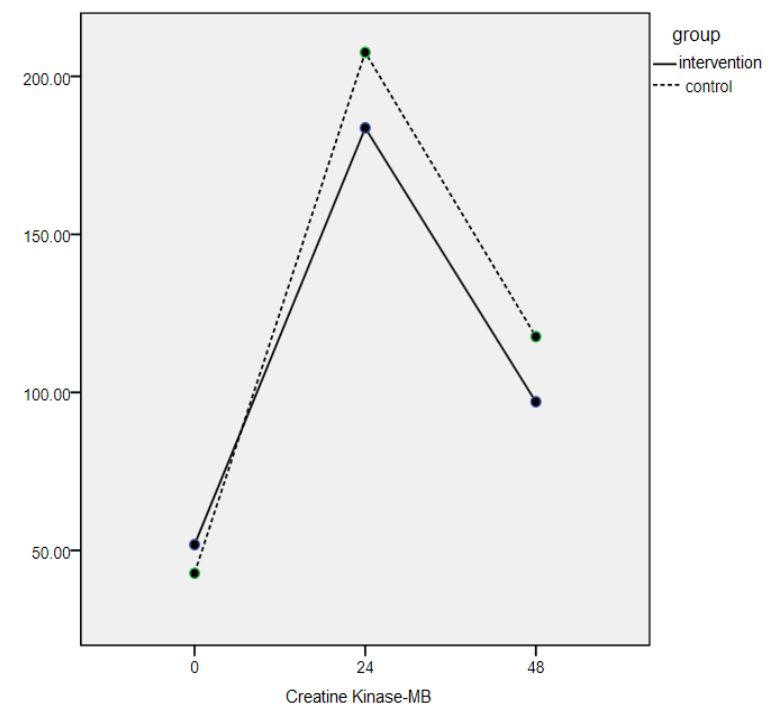

Fig. 2. Changes in creatine kinase-MB enzyme during time between the 2 groups

\section{Discussion}

In this study, there was no statistically significant difference in the level of creatine kinase-MB in the 2 groups at admission, 12 hours and 24 hours after admission. Also, no statistically significant difference was found in the levels of troponin I in the 2 groups at the time of admission, 24 hours and 48 hours after admission. Oxygen is a vasoactive drug and should be used only if there is an indication. Recently, there have been some suggestions regarding the physiological harms of oxygen, but little clinical documentation is available in this regard. Therefore, this was the first study to investigate the impact of oxygen therapy on changes in creatine kinase-MB and troponin I in patients with acute myocardial infarction in Iran.

The results of this study showed that the levels of creatine kinase-MB and troponin I in the 2 groups under study within the first 24 hours and 48 hours after admission to CCU had an increasing trend. Also, it was found that receiving supplemental oxygen or air-oxygen did not have any impact on the changes of these enzymes, and there was no statistically significant difference between the 2 groups. Nonetheless, clinically, the increase in both enzymes was lower in the air-oxygen group than in the supplemental oxygen group. Nehme et al (2015) and Stub et al (2015) conducted studies on patients with acute myocardial infarction to determine their level of creatine kinase-MB and found that patients with myocardial ischemia who received supplemental oxygen had a higher level of creatine kinase-MB enzyme than patients breathing regular air $(19,20)$, which was not consistent with the results of the present study.

Higher level of creatine kinase-MB enzyme could be due to the heterogeneity in the methods of oxygen administration in studies. For example, in the study conducted by Nehme et al, patients in the supplemental oxygen group received 8 liters of oxygen per minute in the ambulance until arriving at the hospital. After entering the hospital, they received oxygen according to the ward protocols. In the air-oxygen group, patients did not undergo oxygen therapy before and after entering the ward, unless their arterial oxygen saturation level was below 94\% and they received oxygen therapy (19). Moreover, according to Stub et al, patients in the supplemental oxygen group received 8 liters of oxygen through mask from the moment they entered the cardiac catheterization ward until 
being transferred to the cardiology ward. The other group only received oxygen via mask in case of a drop in arterial oxygen saturation level to less than $94 \%$ ( 8 liters per minute) or nasal cannula (4 liters per minute) (20). However, in the present study, the patients were not under oxygen therapy before being transferred to CCU.

Similarly, regarding the level of troponin I, the results reported by Ranchordet al (2012) and Hofmann et al (2017) were consistent with those of the present study (9, 21), but the results reported by Nehme et al (2015) were inconsistent with those of the present study (19). During oxygen therapy, depending on the amount of oxygen received, changes will occur in the cardiac output, left ventricular perfusion, and the subsequent release of enzymes. The mentioned changes are such that the delivery of 8 liters of oxygen per minute can reduce the cardiac output by $10 \%$, and the amount of left ventricular perfusion by $16 \%$. Decrease in cardiac output and left ventricular perfusion can also result in a decrease in oxygen supply to the heart and other body systems (11\% reduction).

Therefore, myocardial damage can be a predictable incident that occurs with enzyme release (22). In the present study, no significant difference was observed in enzyme levels in the 2 groups; however, clinically, the levels of both enzymes were higher in supplemental oxygen group patients, which might have been due to oxygen intake for a long time. In other words, the dose of oxygen received and the duration of oxygen therapy are the predicting factors of myocardial damage. Previous studies have shown that receiving every100 liters of oxygen can increase the amount of creatine kinase-MB release by $1.2 \%$. Moreover, receiving oxygen within the first 12 hours after admission to the ward can increase the release of creatine phosphokinase by $1.1 \%$ (19).

\section{Limitations}

Due to small sample size in this study and not examining other outcomes of oxygen therapy, such as the occurrence of arrhythmia, frequent chest pain, use of analgesics and the mortality rate after discharge, the effectiveness or ineffectiveness of the administered supplemental oxygen cannot be determined with certainty.

Therefore, it is recommended to conduct future clinical trial studies with more samples and to assess more outcomes in order to determine whether oxygen administration is helpful or harmful.

\section{Conclusion}

Despite the common belief among nurses that administering supplemental oxygen can be useful for the patients with myocardial infarction, oxygen administration does not play a role in reducing the size of the infarction area. Furthermore, the results of this study showed that the enzyme levels in the oxygen receptor group were slightly lower than those in the other group. Therefore, the administration of oxygen with monitoring SPO2 level can be a more effective care.

\section{Acknowledgment}

This study was extracted from a thesis written by
Fatemeh Poorahmadieh for a master's degree (code No.96.8.6.5625, Trial Registration Number: IRCT 20180321039134N1). The study was financially supported by Shahid Sadoughi University of Medical Sciences, Yazd, Iran. The author would like to thank the researchers of this study including all CCU nurses and patients in Zeyaei hospital, Ardakan, for their collaboration in this study.

\section{Conflict of Interests}

The authors declare that they have no competing interests.

\section{References}

1.Stub D, Smith K, Bernard S, Bray JE, Stephenson M, Cameron P, et al. A randomized controlled trial of oxygen therapy in acute myocardial infarction Air Verses Oxygen In myocardial infarction study (AVOID Study). Am Heart J. 2012;163:339-45.

2.Mozaffarian D, Benjamin EJ, Go AS, Arnett DK, Blaha MJ, Cushman M, et al. Executive summary: heart disease and stroke statistics-2015 update. Circulation. 2015;131:434-41.

3.Shahsavari S, Nazari F, Karimyar Jahromi M, Sadeghi M. Epidemiologic study of hospitalized cardiovascular patients in Jahrom hospitals in 2012- 2013. Cardiovasc Nurs J. 2013;2:14-21.

4. Ambrose JA, Singh M. Pathophysiology of coronary artery disease leading to acute coronary syndromes. F1000 Prime Rep. 2015;7(08):15.

5. Cabello JB, Burls a, Emparanza JI, Bayliss S, Quinn T. Oxygen therapy for acute myocardial infarction. Cochrane Database Syst Rev. 2010;16:CD007160.

6. Danchin N, Chemla D. Challenging doctors' lifelong habits may be good for their patients: oxygen therapy in acute myocardial infarction. Heart. 2009;95(3):176-7.

7. Stub D, Smith K, Bernard S, Nehme Z, Stephenson M, Bray JE, et al. Air versus oxygen in ST-segment elevation myocardial infarction. Circulation. 2015;131:2143-50.

8.Raut MS, Maheshwari A. Oxygen supplementation in acute myocardial infarction: To be or not to be? Ann Card Anaesth. 2016;19:342-44.

9. Ranchord AM, Argyle R, Beynon R, Perrin K, Sharma V, Weatherall $\mathrm{M}$, et al. High-concentration versus titrated oxygen therapy in STelevation myocardial infarction: a pilot randomized controlled trial. Am Heart J. 2012;163:168-75.

10.Stone GW, Martin JL, de Boer MJ, Margheri M, Bramucci E, Blankenship JC, et al. Effect of supersaturated oxygen delivery on infarct size after percutaneous coronary intervention in acute myocardial infarction. Circ Cardiovasc Interv. 2009;2:366-75.

11.Moradkhan R, Sinoway LI. Revisiting the Role of Oxygen Therapy in Cardiac Patients. J Am Coll Cardiol. 2010;56:1013-6.

12. Sepehrvand N, Ezekowitz JA. Oxygen therapy in acute myocardial infarctions: do we need to re-evaluate its necessity? Expert Rev Cardiovasc Ther. 2018;16:693-94

13. Kones R. Oxygen therapy for acute myocardial infarction - then and now. A century of uncertainty. Am J Med. 2011;124(11):1000-5.

14.Khoshnood A, Carlsson M, Akbarzadeh M, Bhiladvala P, Roijer A, Bodetoft S, et al. The Effects of Oxygen Therapy on Myocardial Salvage in ST Elevation Myocardial Infarction Treated with Acute Percutaneous Coronary Intervention: The Supplemental Oxygen in Catheterized Coronary Emergency Reperfusion (SOCCER) Study. Cardiology. 2015;132:16-21.

15. Cabello JB, Burls a, Emparanza JI, Bayliss S, Quinn T. Oxygen therapy for acute myocardial infarction. Cochrane Database Syst Rev. 2013;21:CD007160.

16. Shuvy M, Lotan C. Oxygen therapy in myocardial infarction? Still waiting for an answer. Cardiology. 2015;132:68-70.

17. Metcalfe M. Improving the safety of oxygen therapy in the treatment of acute myocardial infarctions. Int Emerg Nurs. 2012;20:94-7.

18. Wong M, Elliott $\mathrm{M}$. The use of medical orders in acute care oxygen therapy. Br J Nurs. 2009;18:462-4.

19. Nehme Z, Stub D, Bernard S, Stephenson M, Bray JE, Cameron P, et al. Effect of supplemental oxygen exposure on myocardial injury in ST-elevation myocardial infarction. Heart. 2016;102:444-51.

20.Stub D, Smith K, Bernard S, Nehme Z, Stephenson M, Bray J, et al 
Air versus oxygen in myocardial infarction (AVOID) trial sub-study: time-dependent effect of oxygen administration on myocardial injury. Heart Lung Circul. 2015;24:S374.

21.Hofmann R, James SK, Jernberg T, Lindahl B, Erlinge D, Witt N, et al. Oxygen Therapy in Suspected Acute Myocardial Infarction. N Engl J Med. 2017;377:1240-9.

22. Bodetoft S, Carlsson M, Arheden H, Ekelund U. Effects of oxygen inhalation on cardiac output, coronary blood flow and oxygen delivery in healthy individuals, assessed with MRI. Eur J Emerg Med. 2011;18:25-30. 